\title{
PENGARUH LINGKUNGAN KERJA, KOMPETENSI DOSEN, DAN KUALITAS LAYANAN TERHADAP CITRA PERGURUAN TINGGI
}

\author{
EImie $^{1}$, Uus MD Fadli ${ }^{2}$, Syifa Pramudita Faddila ${ }^{3}$ \\ elmie.hanafi@jayabaya.ac.id \\ uus.fadli@ubpkarawang.ac.id \\ Syifa.pramudita@ubpkarawang.ac.id \\ Universitas Jayabaya \\ Universitas Buana Perjuangan Karawang
}

\begin{abstract}
ABSTRAK
Citra yang baik merupakan faktor pendukung utama keberhasilan suatu institusi pendidikan tinggi untuk mampu mempertahankan keberadaannya serta mengembangkan berbagai programnya. Tujuan penelitian ini untuk menjelaskan kualitas lingkungan kerja, kompetensi dosen, kualitas layanan serta hubungan dari ketiga variable dalam membangun citra fakultas dalam sebuah perguruan tinggi. Penelitian ini dilaksanakan pada fakultas ekonomi dari dua fakultas yang ada di dua universitas yang ada di Jakarta dan di Karawang. Populasi adalah seluruh mahasiswa yang ada di seluruh fakultas tersebut. Jumlah sampel sebanyak 255 orang yang diambil secara proporsional stratified random sampling. Data dianalisis dengan distribusi frekuensi, analisis rentang skala dan analisis regresi berganda. Hasil analisis menunjukkan bahwa seluruh variable memiliki modus kinerja yang baik, hubungannya positif sangat signifikan. Penelitian ini menjelaskan bahwa lingkungan kerja, kompetensi dosen, kualitas layanan berpengaruh positif dan signifikan dalam membangun citra fakultas di perguruan tinggi.
\end{abstract}

Kata Kunci: Ligkungan Kerja, Kompetensi Dosen, Kualitas Layanan, Citra Perguruan Tinggi

\begin{abstract}
A good image is the main supporting factor for the success of a higher education institution to be able to maintain its existence and develop its various programs. The purpose of this study is to explain the quality of the work environment, lecturer competence, service quality and the relationship of the three variables in building the image of the faculty in a university. This research was conducted at the two faculties of economics in two universities in Jakarta and in Karawang. The population is all students in all faculties. The number of samples was 255 people who were taken proportionally with stratified random sampling. Data were analyzed by frequency distribution, scale range analysis and multiple regression analysis. The analysis result shows that all variables have a good performance mode; the positive relationship is very significant. This study explains that the work environment, lecturer competence, service quality has a positive and significant effect in building the image of the faculty in higher education.
\end{abstract}

Keywords: Work Environment, Lecturer Competence, Service Quality, Higher Education Image 


\section{PENDAHULUAN}

Kemampuan untuk menampilkan citra yang baik bagi suatu perguruan tinggi merupakan suatu keharusan yang tidak dapat ditawar-tawar, mengingat kondisi persaingan yang dihadapi dunia pendidikan tinggi Indonesia saat ini sangat kompetitif, tidak saja bersifat lokal, regional maupun global. Salah satu penyebabnya adalah adanya otonomi daerah yang membuat semakin banyak perguruan tinggi baru bermunculan. Sudah menjadi keharusan setiap perguruan tinggi untuk terus meningkatkan kualitas sistem pendidikannya. Salah satu cara yang dapat diterapkan diantaranya adalah melalui tata kelola Perguruan Tinggi yang baik. Yakni meliputi prinsip transparansi, akuntabilitas, tanggung jawab, independensi, dan keadilan. Selain itu untuk mewujudkan kemandirian, perguruan tinggi juga dapat melakukan tranformasi diri menjadi Research University sehingga memiliki banyak sumber pendanaan dari dunia usaha, ataupun menjadikan diri sebagai Entrepreneur University.

Sebuah perguruan tinggi yang bermutu dipengaruhi oleh banyak faktor, diantaranya kualitas dosen, termasuk kualitas layanan dan reativitasnya, kepimpinan, rencana strategis perguruan tinggi, sarana dan prasarana, sistem informasi manajemen, hasil pengabdian pada masyarakat, keuangan, proses manajemen, dan lain sebagainya. Peningkatan kemampuan untuk mengelola dan mengembangkan perguruan tinggi sangat diperlukan, termasuk untuk menggunakan prinsip-prinsip modern yang berorientasi pada kualitas pelayanan. Sistem manajemen mutu pada hakikatnya berarti pada perbaikan terus menerus untuk memperkuat dan mengembangkan mutu tersebut. Pelayanan kepada konsumen sangat dirasa penting dalam industri jasa, seperti yang dikemukakan dalam buku A Passion for Excellecent, bahwa ada dua cara untuk berkompetisi, yaitu memberikan perhatian yang lebih kepada konsumen dengan cara memberikan pelayanan yang superior dan berkualitas, serta inovasi yang terus menerus. Dengan kata lain berorientasi kepada konsumen (Goh \& Khoo, 2005: 5-6).

Pada organisasi jasa termasuk pendidikan tinggi, produk jasa diterima oleh pelanggan pada saat terjadi interaksi antara dosen dengan penerima jasa (mahasiswa), sehingga kompetensi dosen dan kualitas proses pembelajaran dalam bekerja sangat menentukan kualitas produk jasa yang dihasilkan (Frizsimmons, dalam Sahyar, 2009: 133). Perguruan Tinggi di Indonesia dalam hal ini tenaga dosen belum bisa mencurahkan seluruh perhatian secara fokus seratus persen pada pekerjaannya. 
Disebabkan banyak dosen yang bekerja di satu tempat ke tempat lainnya dengan waktu yang sangat sedikit dan beban kerja yang banyak (Setiawati, 2009: 2).

Lingkungan kerja adalah segala sesuatu yang ada disekitar para pekerja atau karyawan yang dapat mempengaruhi kepuasan kerja karyawan dalam melaksanakan pekerjaan (Afandi Pandi, 2016:51), keseluruhan sarana dan prasarana yang mempengaruhi pelaksanaan pekerjaan (Sutrisno Edi, 2017:118) yang dapat mempengaruhi dirinya dalam menjalankan tugas-tugas yang dibebankan. Lingkungan kerja ini meliputi tempat bekerja, fasilitas dan alat bantu kerja, kebersihan, pencahayaan, ketenangan, termasuk juga hubungan kerja antara orang-orang yang ada di tempat kerja tersebut (Edi Sutrisno, 2017:118), air conditioner (AC), penerangan yang memadai dan sebagainya.

Kompetensi adalah keahlian untuk melaksanakan pekerjaan maupun kewajiban yang didampingi dengan keahlian (keterampilan) serta ilmu yang seharusnya dimiliki pekerja (Wibowo, 2007). Kompetensi dosen dijelaskan dalam Surat Keputusan Mendiknas nomor 045/U/2002 tentang Kurikulum Inti Perguruan Tinggi adalah seperangkat tindakan cerdas, penuh tanggungjawab yang dimiliki seseorang sebagai syarat untuk dianggap mampu oleh masyarakat dalam melaksanakan tugas-tugas di bidang pekerjaan tertentu." Seorang dosen dapat dikatakan kompeten dalam melaksanakan tugasnya secara professional, jika dia memiliki kompetensi pedagogik, profesional, kepribadian, sosial, dan institusional (Undang-Undang Republik Indonesia nomor 14 tahun 2005 tentang Guru dan Dosen) yang diperlukan dalam praktek pendidikan, penelitian, dan pengabdian kepada masyarakat. Sedangkan Kualitas pelayanan didefinisikan seberapa jauh perbedaan antara kenyataan dan harapan para pelanggan atas layanan yang diterima (Rosyid, 2010: 20 dan Fandy Tjiptono, 2008).

Pada era keterbukaan seperti sekarang ini perguruan tinggi dituntut untuk mampu menampilkan citra positif sebagai suatu institusi berkualitas yang peduli dengan kondisi masyarakat dan adaptif terhadap berbagai perkembangan maupun tuntutan masyarakat. Sehingga tujuan dari penyusunan dan pelaksanaan program dan aktivitas akademik oleh semua komponen dalam suatu perguruan tinggi, seperti kualitas dosen, pelayanan yang prima kepada mahasiswa, agar mahasiswa dapat menyelesaikan pendidikannya sesuai dengan waktu yang telah ditentukan dan berkualitas. Jika seseorang masuk ke dalam 
suatu sistem perguruan tinggi, bermula dari adanya perhatian, timbul minat, muncul keinginan, lalu masuk dan berakhir dengan adanya kepuasan. Namun citra positif yang tampil pada suatu perguruan tinggi bukan sekedar citra yang bersifat semu, tetapi benarbenar merupakan suatu citra yang harus dimiliki suatu institusi pendidikan tinggi sesuai dengan potensi sumber daya yang dimilikinya (Idrus, 2012). Penelitian ini akan menjelaskan citra perguruan tinggi yang diakibatkan oleh kualitas lingkungan kerja, kompetensi dosen dan kualitas layanannya.

\section{METODE PENELITIAN}

Penelitian ini menggunakan pendekatan deskriptif kuantitatif. Sampel diambil dari mahasiswa yang ada di dua Fakultas Ekonomi yang ada di dua universitas yakni Universitas Jayabaya Jakarta, mewakili universitas yang ada di Ibu Kota Indonesia, sebagai salah satu universitas yang menjadi rujukan nasional. Kemudian Fakultas Ekonomi dan Bisnis Universitas Buana Perjuangan (UBP) Karawang sebagai perwakilan dari universitas yang ada di daerah yang berada di tengah-tengah kota industri. Jumlah sampel sebanyak 255 orang yang diambil secara proporsional stratified random sampling. Universitas Jayabaya sebanyak 80 orang mahasiswa, dan 175 mahasiswa dari UBP Karawang.

Data diambil menggunakan kuesioner berskala likert, skala tertinggi diberi skor 4 dan skala terendah diberi skor 1 . Untuk menguji validitas dan reliabilitas kuesioner dilakukan terhadap 30 orang responden dari kedua universitas tersebut. Sebelum data diolah, terlebih dahulu dilakukan analisis normalitas untuk menguji kemampuan memprediksi populasi yang dianalisis. Pengujian hipotesis dilakukan pada taraf nyata $5 \%$. Selanjutnya data dianalisis menggunakan analisis regresi berganda dengan bantuan SPSS.

\section{HASIL PENELITIAN}

\section{Analisis Validitas dan Reliabilitas}

Keabsahan (validitas) dan keajegan (reliabilitas) kuesioner sangat diperlukan untuk menguji kualitas kuesioner yang akan digunakan dalam penelitian ini. Hasil analisis validitas ditampilkan pada tabel 1 , sedangkan uji reliabitas ditampilkan pada tabel 2 di bawah ini. 
Tabel 1. Hasil Uji Validitas

\begin{tabular}{lcc|ccc}
\hline Butir Pernyataan & r hitung & Penjelasan & $\begin{array}{c}\text { Butir } \\
\text { Pernyataan }\end{array}$ & r hitung & Penjelasan \\
\hline Pernyataan X1_1 & 0.370 & valid & Pernyataan X3_1 & 0.470 & valid \\
Pernyataan X1_2 & 0.386 & valid & Pernyataan X3_2 & 0.364 & valid \\
Pernyataan X1_3 & 0.502 & valid & Pernyataan X3_3 & 0.532 & valid \\
Pernyataan X1_4 & 0.571 & valid & Pernyataan X3_4 & 0.658 & valid \\
Pernyataan X1_5 & 0.509 & valid & Pernyataan X3_5 & 0.584 & valid \\
Pernyataan X1_6 & 0.445 & valid & Pernyataan X3_6 & 0.636 & valid \\
Pernyataan X1_7 & 0.500 & valid & Pernyataan X3_7 & 0.370 & valid \\
Pernyataan X1_8 & 0.523 & valid & Pernyataan X3_8 & 0.379 & valid \\
Pernyataan X1_9 & 0.410 & valid & Pernyataan X3_9 & 0.480 & valid \\
Pernyataan X1_10 & 0.397 & valid & Pernyataan X3_10 & 0.583 & valid \\
\hline Pernyataan X2_1 & 0.420 & valid & Pernyataan Y_1 & 0.453 & valid \\
Pernyataan X2_2 & 0.472 & valid & Pernyataan Y_2 & 0.440 & valid \\
Pernyataan X2_3 & 0.410 & valid & Pernyataan Y_3 & 0.553 & valid \\
Pernyataan X2_4 & 0.467 & valid & Pernyataan Y_4 & 0.553 & valid \\
Pernyataan X2_5 & 0.516 & valid & Pernyataan Y_5 & 0.470 & valid \\
Pernyataan X2_6 & 0.612 & valid & Pernyataan Y_6 & 0.510 & valid \\
Pernyataan X2_7 & 0.652 & valid & Pernyataan Y_7 & 0.627 & valid \\
Pernyataan X2_8 & 0.627 & valid & Pernyataan Y_8 & 0.682 & valid \\
Pernyataan X2_9 & 0.579 & valid & Pernyataan Y_9 & 0.703 & valid \\
Pernyataan X2_10 & 0.620 & valid & Pernyataan Y_10 & 0.607 & valid \\
\hline
\end{tabular}

Tabel 2 Hasil Uji Reliabilitas

\begin{tabular}{lcc}
\hline \multicolumn{1}{c}{ Variabel } & $\begin{array}{c}\text { Nilai Alpha } \\
\text { Cronbach }\end{array}$ & Keterangan \\
\hline Variabel Lingkungan Kerja (X1) & 0.786 & Reliabel \\
Variabel Kompetensi Dosen (X2) & 0.843 & Reliabel \\
Variabel Kualitas Layanan (X3) & 0.821 & Reliabel \\
Variabel Citra (Y) & 0.855 & Reliabel \\
\hline
\end{tabular}

Dari tabel 1 tersebut dapat dijelaskan bahwa seluruh butir pernyataan dinilai valid karena nilai $\mathrm{r}_{\text {hitung }} \geq 0,3$. Analisis reliabilitas dilakukan dengan menggunakan Alpha Cronbach $\geq 0,6$ dan semua kuesioner reliabel (Tabel 2) untuk dilanjutkan dalam pengambilan data pada sampel terpilih. 


\section{Analisis Deskriptif}

Analisis deskriptif berperan untuk menjelaskan kondisi setiap variabel pada saat peneltian, meliputi kualitas lingkungan kerja, kompetensi dosen, kualitas layanan serta citranya pada perguruan tinggi yang diteliti.

Tabel 3 Lingkungan Kerja (X1)

\begin{tabular}{|c|c|c|c|}
\hline No & $\begin{array}{c}\text { Deskripsi } \\
\text { Kuesioner }\end{array}$ & $\begin{array}{l}\text { Total } \\
\text { Skor }\end{array}$ & Ket* \\
\hline 1. & $\begin{array}{l}\text { Pencahayaan } \\
\text { ruangan }\end{array}$ & 591 & $\begin{array}{l}\text { Cukup } \\
\text { Baik }\end{array}$ \\
\hline 2. & $\begin{array}{l}\text { Kelembaban } \\
\text { ruangan }\end{array}$ & 592 & $\begin{array}{l}\text { Cukup } \\
\text { Baik }\end{array}$ \\
\hline 3. & Kebisingan & 738 & Baik \\
\hline 4. & Pewarnaan ruangan & 729 & Baik \\
\hline 5. & Ruang gerak & 760 & Baik \\
\hline 6. & Fasilitas & 819 & Baik \\
\hline 7. & Bau-bauan & 666 & Baik \\
\hline 8. & $\begin{array}{l}\text { Hubungan dengan } \\
\text { pemimpin }\end{array}$ & 753 & Baik \\
\hline 9. & $\begin{array}{l}\text { Hubungan dengan } \\
\text { sesama rekan kerja }\end{array}$ & 768 & Baik \\
\hline 10. & $\begin{array}{l}\text { Komunikasi antar } \\
\text { pegawai }\end{array}$ & 770 & Baik \\
\hline \multicolumn{2}{|c|}{$\begin{array}{c}\text { Modus Lingkungan } \\
\text { Kerja }\end{array}$} & - & Baik \\
\hline
\end{tabular}

$*$ Ket $=$ Keterangan
Tabel 4 Kualitas Dosen (X2)

\begin{tabular}{|c|c|c|c|}
\hline No & Deskripsi Kuesioner & $\begin{array}{l}\text { Total } \\
\text { Skor }\end{array}$ & Ket* \\
\hline 1. & $\begin{array}{l}\text { Kemampuan menghidupkan suasana } \\
\text { kelas }\end{array}$ & 744 & Baik \\
\hline 2. & $\begin{array}{l}\text { Kejelasan penyampaian materi dan } \\
\text { jawaban terhadap pertanyaan di } \\
\text { kelas }\end{array}$ & 769 & Baik \\
\hline 3. & $\begin{array}{l}\text { Kesesuaian nilai yang diberikan } \\
\text { dengan hasil belajar }\end{array}$ & 777 & Baik \\
\hline & Kemampuan menjelaskan & & \\
\hline 4. & $\begin{array}{l}\text { keterkaitan topik perkuliahan dengan } \\
\text { konteks kehidupan. }\end{array}$ & 791 & Baik \\
\hline 5. & $\begin{array}{l}\text { Penguasaan akan isu-isu mutakhir } \\
\text { dalam bidang yang diajarkan. }\end{array}$ & 774 & Baik \\
\hline 6. & Kewibawaan sebagai pribadi dosen & 797 & Baik \\
\hline 7. & $\begin{array}{l}\text { Adil dalam memperlakukan } \\
\text { mahasiswa }\end{array}$ & 797 & Baik \\
\hline 8. & $\begin{array}{l}\text { Kemampuan mengendalikan diri } \\
\text { dalam berbagai situasi dan kondisi }\end{array}$ & 795 & Baik \\
\hline 9. & $\begin{array}{l}\text { Mengenal dengan baik mahasiwa } \\
\text { yang mengikuti kuliahnya }\end{array}$ & 779 & Baik \\
\hline \multirow[t]{2}{*}{10.} & $\begin{array}{l}\text { Mudah bergaul dengan kalangan } \\
\text { sejawat, karyawan, dan mahasiswa }\end{array}$ & 795 & Baik \\
\hline & Modus Kualitas Dosen & - & Baik \\
\hline
\end{tabular}

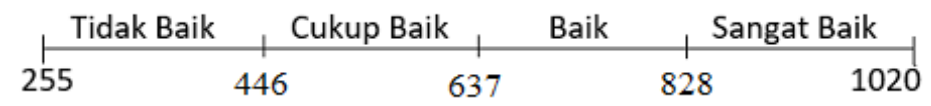

Gambar 1. Garis Skala untuk Membaca Total Skor

Tabel 3 menunjukan bahwa kualitas pencahayaan dan kelembaban yang dipergunakan untuk aktivitas akademik dari kedua perguruan tinggi direspon cukup baik sehingga perlu ditingkatkan minimal menjadi baik. Bau-bauan yang berkaitan dengan kelancaran aktivitas perkuliahan dinilai dibawah nilai 700 sehingga perlu ditingkatkan pada skor yang lebih tinggi agar mahasiswa dan dosen merasa nyaman melaksanakan pembelajran di kelas. Sedangkan untuk indikator lainya sudah dinilai respoden dengan kualitas yang baik. Kemudian dari tabel 4 dapat dijelaskan bahwa secara keseluruhan kualitas dosen dari ketiga fakultas yang diteliti memiliki kualifikasi yang baik. Kualitas 
dosen secara keseleruhan masih perlu ditingkatkan menjadi sangat baik di waktu mendatang.

Tabel 5 Kualitas Layanan (X3)

\begin{tabular}{|c|c|c|c|}
\hline No & Deskripsi Kuesioner & $\begin{array}{l}\text { Total } \\
\text { Skor }\end{array}$ & Ket* \\
\hline 1. & $\begin{array}{l}\text { Layanan fasilitas akademik } \\
\text { (ruang kuliah, peralatan } \\
\text { perkuliahan, perpustakaan, dll) }\end{array}$ & 605 & $\begin{array}{c}\text { Cukup } \\
\text { Baik }\end{array}$ \\
\hline 2. & $\begin{array}{l}\text { Layanan sarana pendukung } \\
\text { akademik (mushola, toilet, } \\
\text { kantin, parkir, dll). }\end{array}$ & 612 & $\begin{array}{c}\text { Cukup } \\
\text { Baik }\end{array}$ \\
\hline 3. & $\begin{array}{l}\text { Kedisiplinan dosen dalam } \\
\text { ketepatan waktu mengajar. }\end{array}$ & 711 & Baik \\
\hline 4. & $\begin{array}{l}\text { Kemampuan layanan tenaga } \\
\text { kependidikan }\end{array}$ & 698 & Baik \\
\hline 5. & Kemudahan layanan Dosen & 739 & Baik \\
\hline 6. & $\begin{array}{l}\text { Cepat tanggap dari kejadian } \\
\text { mendadak (mati lampu, LCD } \\
\text { mati, alat tulis, dan lainnya). }\end{array}$ & 712 & Baik \\
\hline 7. & $\begin{array}{l}\text { Pegetahuan dan kecakapan } \\
\text { dosen dalam memberikan } \\
\text { informasi. }\end{array}$ & 750 & Baik \\
\hline 8. & Perasaan aman mahasiswa. & 743 & Baik \\
\hline 9. & $\begin{array}{l}\text { Hubungan akrab antara } \\
\text { mahasiswa, dosen dan tenaga } \\
\text { kependidikan }\end{array}$ & 757 & Baik \\
\hline 10. & $\begin{array}{l}\text { Kemampuan mengenali dan } \\
\text { memenuhi kebutuhan } \\
\text { mahasiswanya. }\end{array}$ & 738 & Baik \\
\hline \multicolumn{3}{|c|}{ Modus Kualitas Layanan } & Baik \\
\hline
\end{tabular}

Tabel 6 Citra Perguruan Tinggi (Y)

\begin{tabular}{|c|c|c|c|}
\hline No & Deskripsi Kuesioner & $\begin{array}{l}\text { Total } \\
\text { Skor }\end{array}$ & Ket* \\
\hline 1. & $\begin{array}{l}\text { Citra baik dari perguruan } \\
\text { Tinggi }\end{array}$ & 773 & Baik \\
\hline 2. & $\begin{array}{l}\text { Pengenalan oleh } \\
\text { masyarakat luas. }\end{array}$ & 811 & Baik \\
\hline 3. & $\begin{array}{l}\text { Biaya perkuliah } \\
\text { dibanding pesaingnya }\end{array}$ & 761 & Baik \\
\hline 4. & $\begin{array}{l}\text { Perbandingan biaya } \\
\text { pendidikan dan } \\
\text { pelayanan }\end{array}$ & 714 & Baik \\
\hline 5. & Lokasi & 798 & Baik \\
\hline 6. & Sarana dan prasarana & 732 & Baik \\
\hline 7. & $\begin{array}{l}\text { Kelengkapan media } \\
\text { informasi dan informatif. }\end{array}$ & 735 & Baik \\
\hline 8. & $\begin{array}{l}\text { Kualiats Pelayanan } \\
\text { Tenaga kependidikan }\end{array}$ & 780 & Baik \\
\hline 9. & $\begin{array}{l}\text { Cepat tanggap Tenaga } \\
\text { kependidikan mengatasi } \\
\text { keluhan mahasiswa. }\end{array}$ & 724 & Baik \\
\hline 10. & $\begin{array}{l}\text { Penilian citra atau image } \\
\text { secara keseluruhan }\end{array}$ & 773 & Baik \\
\hline \multicolumn{3}{|c|}{ Modus Citra Perguruan Tinggi } & Baik \\
\hline
\end{tabular}

\begin{tabular}{|c|c|c|c|}
\hline Tidak Baik & Cukup Baik & Baik & Sangat Baik \\
\hline 255 & & & 1020 \\
\hline
\end{tabular}

Gambar 2. Garis Skala untuk membaca Total Skor

Dari tabel 5 diketahui bahwa kualitas layanan perguruan tinggi yang dinilai masih cukup adalah (1) layanan fasilitas akademik (ruang kuliah, peralatan perkuliahan, perpustakaan, dll); dan (2) layanan sarana pendukung akademik (mushola, toilet, kantin, parkir, dll). Kemudian skor yang masih rendah walau sudah dinilai baik adalah (1) kemampuan layanan tenaga kependidikan; (2) kedisiplinan dosen dalam ketepatan waktu mengajar; dan (3) kecepat-tanggapan dari tenaga kependidikan pada saat kejadian mendadak seperti mati lampu, LCD mati, kekurangan alat tulis, dan lainnya pada saat perkuliahan sedang berjalan. Sedangkan indikator layanan lainya dinilai baik. 
Dari tabel 6 dapat dijelaskan bahwa bahwa dimensi citra perguruan tinggi, dimensi biaya, dimensi lokasi, dimensi sarana prasarana dan dimensi pelayanan staf di nilai baik oleh para responden, hal ini menunjukkan bahwa citra dari ketiga perguuran tinggi yang diteliti sudah baik.

\section{Analisis Hubungan Antar Variabel}

Tabel 7 menjelaskan hasil analisis regresi berganda, mengenai pengaruh lingkungan kerja $\left(\mathrm{X}_{1}\right)$, kompetensi dosen $\left(\mathrm{X}_{2}\right)$ dan kualitas layanan $\left(\mathrm{X}_{3}\right)$ terhadap citra perguruan tinggi $(\mathrm{Y})$.

Tabel 7 Hasil Regresi Linier Berganda

\begin{tabular}{|c|c|c|c|c|}
\hline Variabel Bebas & $\begin{array}{l}\text { Koefisien } \\
\text { Regresi }\end{array}$ & $\mathbf{t}$ hitung & Sig & $\begin{array}{c}\text { Koefisien } \\
\text { Determinasi } \\
\text { Parsial (r) }\end{array}$ \\
\hline Konstanta & 0.476 & & & \\
\hline Lingkungan Kerja (X1) & 0.264 & 3.874 & 0.0005 & .238 \\
\hline Kompetensi Dosen (X2) & 0.140 & 2.201 & 0.029 & .138 \\
\hline Kualitas Layanan (X3) & 0.644 & 10.737 & 0.0005 & .561 \\
\hline Koefisien Korelasi (R ) & \multicolumn{4}{|c|}{0.790} \\
\hline Adjusted R Square & \multicolumn{4}{|c|}{0.620} \\
\hline $\mathrm{F}_{\text {hitung }}$ & \multicolumn{4}{|c|}{139.041} \\
\hline Sig. F & \multicolumn{4}{|c|}{0.0005} \\
\hline $\begin{array}{l}\text { Persamaan Regresi: } \\
Y=0.476+0.264 X 1+0.14\end{array}$ & & & & \\
\hline
\end{tabular}

Koefisien korelasi (R) sebesar 0.790 menjelaskan adanya korelasi yang kuat dan positif dari lingkungan kerja $\left(\mathrm{X}_{1}\right)$, kompetensi dosen $\left(\mathrm{X}_{2}\right)$, dan kualitas layanan $\left(\mathrm{X}_{3}\right)$ terhadap citra perguruan tinggi $(\mathrm{Y})$ yang diteliti. Kontribusi variabel bebas terhadap variabel terikatnya dapat dilihat dari Adjusted $R$ Square sebesar angka 0.620. Hal ini menunjukkan bahwa sebesar $62,0 \%$, citra perguruan tinggi dapat dijelaskan oleh variabel lingkungan kerja, kompetensi dosen, dan kualitas layanan. Sedangkan sisanya sebesar 38\% dipengaruhi oleh variabel lain yang tidak diteliti.

Hasil uji anova sebesar Sig.F $=0,0005$. Hal ini menunjukkan bahwa ketiga variabel independen secara signifikan memilikli hubungan yang simultan terhadap citra fakultas dari perguruan tinggi yang diteliti. 


\section{KESIMPULAN}

Kualitas lingkungan kerja, kompetensi dosen, dan kuliatas layanan dari kedua fakultas yang diteliti pada kondisi yang baik sehingga menghasilkan citra perguruan tinggi yang baik pula. Ketiga variabel independent secara bersama-sama dan sangat signifikan berperan positif dalam membangun citra perguruan tinggi. Hasil penelitian ini menjelaskan bahwa untuk menghasilkan citra fakultas dan perguruan tingggi yang baik dapat dibangun melalui peningkatan kualitas lingkungan kerja agar dosen, tenaga kependidikan dan mahasiswa dapat melakukan aktivitas tridarma perguruan tinggi yang baik, perbaikan kualitas dosen agar mampu melaksanakan transfer knowlwdge dengan baik serta memperbaiki kualitas layanannya.

\section{DAFTAR PUSTAKA}

Afandi, Pandi. (2016). Concept \& Indicator Resources Managemen. Deepublish : Yogjakarta.

Goh, Sunny T.H. - Khoo Kheng Hor. (2003). Marketing Wise. Jakarta, Gramedia Pustaka.

Idrus, Syech. (2012). Citra Positif Perguruan Tinggi Dapat dibangun Melalui Sistem Penjaminan Mutu Internal, http://syechidrus.wordpress.com,

Rosyid, Rum. (2010). Struktur perbaikan kualitas: TQM dalamPendidikan. Karya Ilmiah, Kementrian Pendidikan Nasional Universitas Tanjung Pura Fakultas Keguruan dan Ilmu Pendidikan.

Sahyar. (2009). Pengaruh Kompetensi Dosen dan Proses Pembelajaran Terhadap Kepuasan Mahasiswa. Pekbis Jurnal, Vol. 1, No. 3, November 2009, hal 131-139.

Setiawati, Teti. (2009). Pengaruh Kompetensi Kerja Dosen Teerhadap Kinerja Dosen (Studi Kasus di FPTK UPI). Media Pendidikan, Gizi, dan Kuliner, Vol 1, No 1, Oktober 2009.

Sutrisno, Edi. (2017). Manajemen Sumber Daya Manusia. Jakarta. Perbit : Kencana.

Tjiptono, Fandy. (2008). Strategi Pemasaran. Yogyakarta, Penerbit : Andi, Edisi ke Tiga.

Wibowo. (2007). Manajemen Kinerja. Jakarta. PT. Raja Grafindo Persada. 